\title{
ANALISA PENGENDALIAN PERSEDIAAN BAHAN BAKU STEEL SCRAP PADA INDUSTRI PENGECORAN LOGAM
}

\author{
Solihin', Ibnu Bari Taqi' ${ }^{2}$, Muchammad Fauzi ${ }^{3}$ \\ Program Studi Teknik Industri ${ }^{1,2,3}$ \\ Universitas Widyatama \\ Jl Cikutra no 204A, Kota Bandung \\ $\underline{\text { Sholihinc17@gmail.com }}$, ibataqi@gmail.com ${ }^{2}$, Muchammad.fauzi@ widyatama.ac.id ${ }^{3}$
}

\begin{abstract}
Abstrak
Steel scrap adalah bahan bahan sisa (waste) dari hasil proses produksi industri yang bergerak dalam bidang press atau stamping untuk komponen otomotiv. Walaupun menurut perusahaan stamping steel scrap di anggap sampah, bagi perusahaan hulu seperti industri pengecoran logam steel scrap adalah bahan baku yang menjadi kebutuhan produksi yang memegang peranan penting bagi kelangsungan produksi perusahaan yang bergerak dalam bidang pengecoran logam. Permasalahan yang terjadi pada perusahaan pengecoran logam adalah biaya bahan baku meningkat karena kekurangan Steel scrap. Kebutuhan Steel scrap sendiri dipengaruhi oleh demand yang memiliki fluktuasi yang tinggi dan cenderung tak tentu (uncertainty). Pemilihan metode inventori tak tentu diharapkan bisa memberikan gambaran keuntungan yang optimal.
\end{abstract}

Tujuan dari penelitian ini untuk mengetahui jumlah pembelian bahan baku paling ekonomis dalam jangka waktu satu tahun dan bisa memprediksi pembelian di tahun tahun berikutnya. Lokasi penelitian ini dilakukan pada salah satu perusahan pengecoran logam yang berada di Karawang Jawa Barat.

Kata kunci:

Steel Scrap, Uncertaint

\begin{abstract}
Steel scrap is waste product from the results of industrial production processes at manufacture industries for automatic components. Although according to manufacture companies, steel scrap considered as garbage or waste material, except for
\end{abstract}

upstream companies such as steel casting manufacture steel scrap considered as raw materials. To fullfill production needs, steel scrap play an important role for the continuity

of production companies engaged in metal casting. The problem that occasionally occurs in metal casting companies is sometimes the cost of raw materials increases due to lack of steel scrap. The needs for steel scrap itself is influenced by production demands that have high fluctuation and tend to be uncertain. Uncertainty inventory method expected to provide an optimal profit picture.

The purpose of this study is to determine the number of purchases of the most economical raw materials within one year and predict purchases in the following years. The location of this research was conducted at a metal casting company located in Karawang, West Java.

Keywords:

Steel Scrap, Uncertainty

\section{Pendahuluan}

Kebutuhan akan sarana transportasi terus meningkat yang dibuktikan dengan semakin meningkatnya penjualan otomotive dari tahun ketahun meskipun krisis ekonomi global belum berakhir. Kebutuhan suku cadang dari otomotive juga terus meningkat sehingga proses

produksi juga harus diperbaiki sistem maupun kulitas dari produk, proses produksi utama dari suku cadang otomotive terutama kendaraan roda 2 dan roda 4 yaitu pengecoran logam. Sedangkan dalam proses pengecoran logam masih banyak kendala terutama

Solihin, Ibnu Bari Taqi, Muchammad Fauzi

Jurnal Ilmiah Teknologi Informasi Terapan

Volume 6, No 2, 15 April 2020 
dalam proses pengadaan material utama proses melting yaitu steel scrap.

Proses melting proses peleburan material seperti steel scrap, pig iron, dan besi paduan dengan cara memanaskannya hingga mencapai titik cair material yang dilebur, berjalan di dalam sebuah unit yang disebut Melting Furnace.

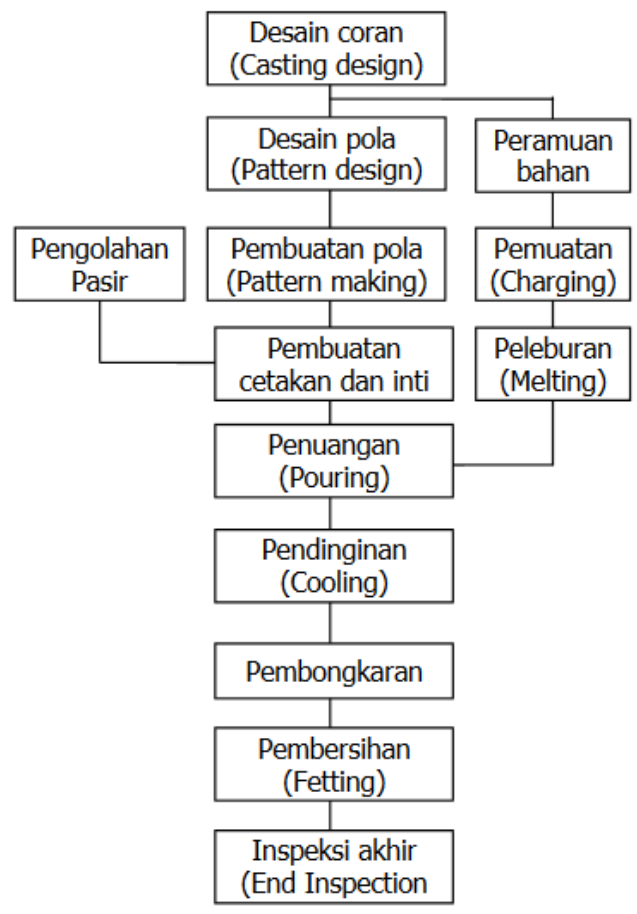

\section{Gambar 1 Urutan proses pengecoran logam}

Oleh karena itu Industri pengecoran logam memerlukan pengendalian persediaan Steel scrap agar tidak mengganggu proses produksi. Pengendalian persediaan Steel scrap sangat dibutuhkan oleh sebuah perusahaan yang bergerak dalam industri pengecoran logam, karena dalam proses produksinya memerlukan bahan baku yang harus selalu tersedia sehingga persediaan Steel scrap sangat diperlukan dalam upaya untuk mengoptimalkan waktu dan biaya dalam pemanfaatan Steel scrap tersebut.

Persediaan Steel scrap merupakan bagian yang sangat penting dalam proses pengecoran logam. Alasannya adalah Steel scrap komponen utama dalam proses metling dan jika dalam proses ini sampai kekungaran Steel scrap maka bukan hanya mempengaruhi waktu produksi tetapi sampai mengganggu kualitas produk.

Rumusan masalah yang penulis kemukakan sebagai fokus penelitian nantinya adalah bagaimana mengoptimalkan persediaan Steel scrap dalam menentukan: (1) Bagaimana menentukan order Steel scrap yang optimal pada industry pengecoran ogam yang memiliki resiko kegagalan dalam proses produksi, (2) Berapa Jumlah Quanity Steel scrap yang harus dibeli dari supplier regular, (3) Berapa Jumlah Quanity Steel scrap yang harus dibeli dari subcon non regular.

Tujuan penelitian yang dilakukan adalah (1) menentukan pemesanan dan memprediksi keuntungan periode selanjutnya, (2) menentukan keuntungan terbaik dalam setiap lot pesanan

\section{KAJIAN LITERATUR}

Penelitian ini dilaksanakan di indutri pengecoran logam PT. ABC berlokasi di salah satu Kawasan industry Karawang - Jawa Barat. Lokasi ini dipilih secara sengaja (purposive) dengan mempertimbagkan bahwa industri ini salah satu industri pengecoran logam terbesar di Jawa Barat.

Pengumpulan data yang dilakukan dalam penelitian ini terdiri atas data primer dimana data-data ini didapatkan dari hasil observasi dan wawancara langsung kepada pengguna dan bagian pengadaan.

Batasan-batasan dalam penelitian ini adalah (1) penelitian ini membahas tentang persediaan pada department purchasing selaku bagian pengadaan PT. $\mathrm{ABC}$, (2) penelitian dan analisa hanya dilakukan pada material Steel scrap, (3) analisa dilakukan dengan menggunakan metode Persediaan Tak tentu (uncertainty).

Asumsi -asumsi dalam penelitian ini adalah (1) lead time waktu pengiriman konstan, (2) tenaga kerja dan sumber daya lainya berjalan lancer, (3) pengiriman bahan baku berjalan dengan lancar sesuai permintaan PT. ABC, (4) kapasitas produksi di asumsikan sama dan tidak bisa diubah. 


\section{AnAlisis dan PERANCANGan}

Data yang dikumpulkan dalam proses penelitian ini dianalisa menggunakan analisa deskriptip yaitu dengan cara menggambarkan atau menguraikan tentang proses melting yang diperoleh dari laporan hasil produksi dan data pembelian department purchasing.

Berdasarkan tujuan yang ingin dicapai dalam penelitian ini, maka model analisa yang digunakan yaitu sebagai berikut:

\section{Inventori tak tentu}

Inventori tak tentu adalah sisten inventori dimana karakteristik fenomenanya tidak diketahui secara lengkap, atau seacara statistic karakteristik parameter populasinya diketahui sebagian. Fenomena ini dapat terjadi baik karena permintaan barang yang tidak beraturan maupun ancang-ancang (lead time) pengadaan barang yang tidak dapat diprediksi dengan akurat. Secara statistik fenomena ini ditandai dengan tidak diketahuinya secara lengkap parameter populasinya baik nilai sentral (ekpektasinya), nilai sebaran (variansi), dan atau pola distribusi kemungkinannya.

\section{Data Actual Produksi}

Data-data yang dikumpulkan berasal dari hasil produksi bulan sebelumnya. Dimana data tersebut berisikan (1) Data pembelian Steel scrap, (2) Data kebutuhan scrap per hari, (3) Data history kekurangan bulan sebelumnnya.

Assauri (2004) pengertian bahan baku meliputi semua bahan yang dipergunakan dalam perusahaan, kecuali terdapat bahan-bahan yang secara fisik akan digabungkan dengan produk yang dihasilkan oleh perusahaan tersebut. Perusahaan yang memiliki penguasaan atas produksi bahan baku sendiri lebih menjamin ketersediaan bahan baku dibandingkan bila pengadaan bahan baku tersebut dilakukan melalui pembelian.

Asal bahan baku Steel scrap didapat dari pengepul didaerah Karawang. Berdasarkan data yang dimiliki oleh department purchasing, Steel scrap yang digunakan berasal dari pengepul bahan bekas di Karawang dengan biaya pembelian Rp. $6.200 / \mathrm{Kg}$. Sedangkan Steel scrap yang dijual kepada pelanggan PT. ABC adalah Rp. $6.800 / \mathrm{Kg}$ serta jika terdapat kelebihan Steel scrap maka akan dijual kembali kepada pengepul lain dengan harga yang cukup rendah dari harga beli yaitu Rp. 5.800/Kg.

\section{Kebutuhan Bahan Baku Steel scrap}

Kebutuhan bahan baku per hari sebenarnya sudah direncanakan 7 hari setiap bulan sebelum proses produksi dan waktu kedatangan adalah 1 hari sebelum proses produksi.

Tabel 1 Data Kebutuhan Steel Scrap

\begin{tabular}{|c|c|c|c|c|}
\hline Tanggal & Hari & $\begin{array}{c}\text { Produksi / } \\
\text { Batch }\end{array}$ & $\begin{array}{c}\text { Penggunaan } \\
\text { Steel Scrap / } \\
\text { Batch }{ }^{*} \mathrm{Kg}\end{array}$ & $\begin{array}{c}\text { Penggunaan } \\
\text { Steel Scrap / } \\
\text { Hari *Kg }\end{array}$ \\
\hline 1 & Senin & 33 & 3,300 & 108,900 \\
\hline 2 & Selasa & 33 & 3,300 & 108,900 \\
\hline 3 & Rabu & 33 & 3,300 & 108,900 \\
\hline 4 & Kamis & 33 & 3,300 & 108,900 \\
\hline 5 & Jumat & 32 & 3,300 & 105,600 \\
\hline 6 & Sabtu & & Libur & \\
\hline 7 & Minggu & & Libur & \\
\hline 8 & Senin & 33 & 3,300 & 108,900 \\
\hline 9 & Selasa & 33 & 3,300 & 108,900 \\
\hline 10 & Rabu & 33 & 3,300 & 108,900 \\
\hline 11 & Kamis & 33 & 3,300 & 108,900 \\
\hline 12 & Jumat & 32 & 3,300 & 105,600 \\
\hline 13 & Sabtu & & Libur & \\
\hline 14 & Minggu & & Libur & \\
\hline 15 & Senin & 33 & 3,300 & 108,900 \\
\hline 16 & Selasa & 33 & 3,300 & 108,900 \\
\hline 17 & Rabu & 33 & 3,300 & 108,900 \\
\hline 18 & Kamis & 33 & 3,300 & 108,900 \\
\hline 19 & Jumat & 32 & 3,300 & 105,600 \\
\hline 20 & Sabtu & & Libur & \\
\hline 21 & Minggu & & Libur & \\
\hline 22 & Senin & 33 & 3,300 & 108,900 \\
\hline 23 & Selasa & 33 & 3,300 & 108,900 \\
\hline 24 & Rabu & 33 & 3,300 & 108,900 \\
\hline 25 & Kamis & 33 & 3,300 & 108,900 \\
\hline 26 & Jumat & 32 & 3,300 & 105,600 \\
\hline 27 & Sabtu & & Libur & \\
\hline 28 & Minggu & & Libur & \\
\hline 29 & Senin & 33 & 3,300 & 108,900 \\
\hline 30 & Selasa & 32 & 3,300 & 105,600 \\
\hline \multicolumn{2}{|c|}{ Jumlah } & 721 & 72,600 & $2,379,300$ \\
\hline
\end{tabular}

Tabel 1. Menunjukan Kebutuhan bahan baku yang cukup konstan perharinya karena dibatasi oleh jam kerja yang sudah baku serta lead time proses melting yang selalu sama setian batch nya.

\section{Pembelian Bahan Baku}

Proses pembelian bahan baku dilakukan langsung kepada pemasok yang ada di Karawang dengan mengirimkan purchase order sebagai bukti yang sah untuk proses pemesana steel scrap. 
Tabel 2 Data Pembelian \& Aktual penjualan Steel scrap ke Customer PT. ABC

\begin{tabular}{|cccc|}
\hline No & Bulan & $\begin{array}{c}\text { Jumlah } \\
\text { Pembelian } \\
\text { Steel Scrap } \\
{ }^{*} \mathrm{Kg}\end{array}$ & $\begin{array}{c}\text { Aktual Jumlah } \\
\text { Penjualan Steel } \\
\text { Scrap }{ }^{*} \mathrm{Kg}\end{array}$ \\
\hline 1 & Januari & $2,379,300$ & $2,051,121$ \\
2 & Februari & $2,186,400$ & $1,922,524$ \\
3 & Maret & $2,379,300$ & $2,338,278$ \\
4 & April & $2,379,300$ & $2,338,278$ \\
5 & Mei & $2,379,300$ & $2,338,278$ \\
6 & Juni & $2,379,300$ & $2,051,121$ \\
7 & Juli & $2,186,400$ & $2,111,007$ \\
8 & Agustus & $2,379,300$ & $2,215,210$ \\
9 & September & $2,379,300$ & $2,010,098$ \\
10 & Oktober & $2,379,300$ & $1,969,076$ \\
11 & November & $2,379,300$ & $2,133,166$ \\
12 & Desember & $2,379,300$ & $2,338,278$ \\
\hline
\end{tabular}

\section{Data Penjualan Bulan Sebelumnya}

Dari Tabel 2. Kita mendapatkan data aktual tahun lalu dan bisa kita jadikan data probabilistik / kemungkinan penjualan tahun untuk tahun berikutnya sehingga penjualan tahun berikutnya diharapkan bisa mendapatkan keuntungan yang maksimal.

Tabel 3 Prediksi permintaan Tahun yang akan datang dan kemungkinanuya

\begin{tabular}{|cccc|}
\hline No & Bulan & $\begin{array}{c}\text { Rencana Jumlah } \\
\text { Penjualan Steel } \\
\text { Scrap }{ }^{*} \text { Kg }\end{array}$ & Kemungkinan \\
\hline 1 & Januari & $2,334,034$ & 0.14 \\
2 & Februari & $2,154,553$ & 0.12 \\
3 & Maret & $2,378,593$ & 0.02 \\
4 & April & $2,378,593$ & 0.02 \\
5 & Mei & $2,378,593$ & 0.02 \\
6 & Juni & $2,334,034$ & 0.14 \\
7 & Juli & $2,183,801$ & 0.03 \\
8 & Agustus & $2,367,984$ & 0.07 \\
9 & September & $2,322,011$ & 0.16 \\
10 & Oktober & $2,308,572$ & 0.17 \\
11 & November & $2,353,838$ & 0.10 \\
12 & Desember & $2,378,593$ & 0.02 \\
& & & \\
\hline
\end{tabular}

\section{Matrik Formula Pay-Off Keuntungan}

Dari hasil analisa dan study terkait data data departement purchasing bisa dibuat data Matrik formula pay-off keuntungan sebagai berikut :
Tabel 4 Pay-Off $\mathrm{X}>\mathrm{Y}$

\begin{tabular}{|l|c|}
\hline & $\mathrm{X}>\mathrm{Y}$ \\
\hline Harga Beli dari Pemasok & $6200 \mathrm{X}$ \\
\hline Harga Jual Ke Pelanggan & $6800 \mathrm{Y}$ \\
\hline Harga Jual Ke Pengepul & $5800(\mathrm{X}-\mathrm{Y})$ \\
\hline Ongkos Kekurangan & 0 \\
\hline Keuntungan & $6800 \mathrm{Y}+5800(\mathrm{X}-\mathrm{Y})-6200 \mathrm{X}$ \\
\hline
\end{tabular}

Tabel 5 Pay-Off $\mathrm{X}=\mathrm{Y}$

\begin{tabular}{|l|c|}
\hline & $\mathrm{X}=\mathrm{Y}$ \\
\hline Harga Beli dari Pemasok & $6200 \mathrm{X}$ \\
\hline Harga Jual Ke Pelanggan & $6800 \mathrm{Y}$ \\
\hline Harga Jual Ke Pengepul & 0 \\
\hline Ongkos Kekurangan & 0 \\
\hline Keuntungan & $6800 \mathrm{Y}-6200 \mathrm{X}$ \\
\hline
\end{tabular}

Tabel 6 Pay-Off X >Y

\begin{tabular}{|l|c|}
\hline & $\mathrm{X}<\mathrm{Y}$ \\
\hline Harga Beli dari Pemasok & $6200 \mathrm{X}$ \\
\hline Harga Jual Ke Pelanggan & $6800 \mathrm{Y}$ \\
\hline Harga Jual Ke Pengepul & 0 \\
\hline Ongkos Kekurangan & $6700(\mathrm{Y}-\mathrm{X})$ \\
\hline Keuntungan & $6800 \mathrm{Y}-6200 \mathrm{X}-6700(\mathrm{Y}-\mathrm{X})$ \\
\hline
\end{tabular}

\section{Tabel Perhitungan Keuntungan}

Dengan data Tabel. 2 dan Tabel 3. Maka bisa kita buat ekpetasi keuntungan setiap pemesanan sebagai berikut:

Tabel 7 Perhitungan Ekpetasi Keuntungan

\begin{tabular}{|c|lr|r|}
\hline $\begin{array}{c}\text { Ukuran } \\
\text { Pemesanan }\end{array}$ & \multicolumn{2}{|c|}{ KEUNTUNGAN } & KETERANGAN \\
\hline \hline 2334034 & $\mathrm{Rp}$ & $1,572,171,434$ & \\
\hline 2154553 & $\mathrm{Rp}$ & $452,581,334$ & \\
\hline 2378593 & $\mathrm{Rp}$ & $1,641,924,714$ & \\
\hline 2378593 & $\mathrm{Rp}$ & $1,641,924,714$ & \\
\hline 2378593 & $\mathrm{Rp}$ & $1,641,924,714$ & \\
\hline 2334034 & $\mathrm{Rp}$ & $1,435,416,797$ & \\
\hline 2183801 & $\mathrm{Rp}$ & $920,375,955$ & \\
\hline 2367984 & $\mathrm{Rp}$ & $1,689,768,045$ & \\
\hline 2322011 & $\mathrm{Rp}$ & $1,516,070,600$ & OPTIMAL \\
\hline 2308572 & $\mathrm{Rp}$ & $1,475,556,321$ & \\
\hline 2353838 & $\mathrm{Rp}$ & $1,534,214,317$ & \\
\hline 2378593 & $\mathrm{Rp}$ & $1,548,555,145$ & \\
\hline & & & \\
\hline
\end{tabular}

Perhitungan bilai ekspektasi untuk ukuran lot pemesanan Steel scrap 2.367.984 kg per tahun adalah:

Solihin, Ibnu Bari Taqi, Muchammad Fauzi 
Tabel 8 Uraian Perhitungan Ekpetasi Keuntungan

\begin{tabular}{|cccccc|}
\hline Keuntungan & \multicolumn{3}{c}{ Kemungkinan } & \multicolumn{2}{r|}{ Kentungan Optimum } \\
\hline $2,710,112,600$ & $\times$ & 0.14 & $=$ & $373,808,634$ \\
$1,207,359,400$ & $\times$ & 0.12 & $=$ & $145,715,790$ \\
$1,431,399,400$ & $\times$ & 0.02 & $=$ & $24,679,300$ \\
$1,431,399,400$ & $\times$ & 0.02 & $=$ & $24,679,300$ \\
$1,431,399,400$ & $\times$ & 0.02 & $=$ & $24,679,300$ \\
$1,386,840,400$ & $\times$ & 0.14 & $=$ & $191,288,331$ \\
$1,236,607,400$ & $\times$ & 0.03 & $=$ & $42,641,634$ \\
$1,420,790,400$ & $\times$ & 0.07 & $=$ & $97,985,545$ \\
$1,734,114,000$ & $\times$ & 0.16 & $=$ & $269,086,655$ \\
$1,824,155,300$ & $\times$ & 0.17 & $=$ & $314,509,534$ \\
$1,520,873,100$ & $\times$ & 0.10 & $=$ & $157,331,700$ \\
$1,355,014,600$ & $\times$ & 0.02 & $=$ & $23,362,321$ \\
\hline \multicolumn{7}{r}{ Keuntungan Optimum } & & & $1,689,768,045$ \\
\hline
\end{tabular}

\section{KESIMPULAN DAN SARAN}

Berdasarkan hasil dan pembahasan maka dapat disimpulkan bahwa (1) Metode Inventori tak tentu cukup efektip untuk melihat keuntungan optimum dalam proses pengendalian bahan baku yang tidak tentu permintaan dan kondisi yang akan dihadapi pada periode selanjutnya dengan melihat jumlah lot pemesanan. (2) Jumlah pemesana Steel scrap sama dengan rencana penjualan Steel scrap ke customer PT. ABC yaitu $2.367 .984 \mathrm{~kg}$ per tahun dengan ekpetasi keuntungan Rp. 1,689,768,045,-. (3) Dari semua martik keuntungna pay-off, pemesanan lot dengan nilai 2,154,553 memiliki keuntungn yang sangan kecil dikarenakan lot pemesanan ini memiliki selisih yang cukup tinggi dengan prediksi demand karena itu biaya ongkos kekurangan yang cukup tinggi dari pada yang lain.

Disarankan ke pada PT. ABC adalah (1) Jumlah pesanan yang bisa digunakan untuk mendapatkan keuntungan optimum dari pengadaan bahan baku Steel scrap adalah $2.367 .984 \mathrm{~kg}$ per tahun. (2) Setiap 3 bulan dihitung kembali dengan metode yang sama untuk memastikan ralita keuntungan tidak jauh berbeda dengan ekspetasi yang sudah di analisa.
Apriyani N. 2017. Analisa Pengendalian Persediaan Bahan Baku Dengan Metode Economic Order Quantity dan Kanban Pada PT. Adyawinsa Stamping Industries. 10:128-142

Rochman DD, Puspani NS, Fauzi M. 2017. Model Praktikum Manajemen Persediaan dan pengadaan. $02: 47-57$

Nur Bahagia, Senator. 2006. Sistem Inventori. Bandung: Penerbit ITB.

\section{REFERENSI}

Assauri. S. 2004. Manajemen Produksi dan Operasi. Lembaga Penerbit FEUI, Jakarta 